\title{
Correlation of Fundus Autofluorescence of the Macula with Visual Outcome after Successful Repair of Rhegmatogenous Retinal Detachment
}

\author{
MARIAM R. FADEL, M.Sc.; SHERIF SHETA, M.D.; ALI M. TAHA, M.D.; HATEM A. SAEED, M.D.; \\ NAHLA B. ABOU HUSSEIN, M.D. and AHMED E. HABIB, M.D.
}

The Department of Ophthalmology, Faculty of Medicine, Cairo University

\begin{abstract}
Background: Successful reattachment of the macula after $\mathrm{RD}$ is often associated with incomplete visual recovery. Even with a normal-appearing macula on examination, patients often experience visual impairment. Fundus autfluorescence has been used to investigate the morphological and functional changes occurring after RD repair following vitrectomy.

Aim of the Work: To investigate the structure-function relationship of the macula, by correlating fundus autofluorescence and visual acuity following successful repair of rhegmatogenous retinal detachment.

Material and Methods: Forty-five eyes underwent surgical repair of RRD followed by FAF imaging one and three months post-operative. FAF findings were correlated with postoperative BCVA.

Results: Forty-five eyes achieved complete post-operative reattachment with $95.6 \%$ SOSR. Mean preoperative logMAR visual acuity showed significant difference with mean postoperative logMAR BCVA ( $p$ 0.001). The values of BCVA showed significant difference between eyes showing hyperautofluorescence on FAF imaging and eyes not showing hyperautofluorescence $(p=0.015)$.

Conclusion: Fundus autofluorescence is a recent noninvasive imaging modality that evaluates the function and health of the photoreceptor and the RPE layers showing great advantage in analyzing the macular function abnormality.
\end{abstract}

Key Words: FAF - Rhegmatogenous retinal detachmentMicrostructural changes - Macula - Visual outcome.

\section{Introduction}

RHEGMATOGENOUS Retinal Detachment (RRD) leads to anatomical distortion of the human retina and consequently, visual impairment. Despite excellent surgical success rates and anatomical

Correspondence to: Dr. Mariam R. Fadel, The Department of Ophthalmology, Faculty of Medicine, Cairo University success with the current modalities of treatment, visual outcomes may still be disappointing [1]

Important predictors of visual recovery after retinal detachment surgery include pre-operative Visual Acuity (VA) and the presence of foveal detachment. Decreased VA after successful repair of retinal detachment may be due to epiretinal membrane, cystoid macular edema, retinal folds, and persistent foveal detachment [2].

Clinical Autofluorescence (AF) is an imaging modality that is able to evaluate the functional status of the retina, in addition to the anatomy. FAF has been advanced as a superior method due to the high contrast that it provides, identifying areas of RPE loss, measurements of atrophy and its progression [3].

FAF proved its efficacy as a noninvasive diagnostic imaging modality, which can monitor the disease progression and explains visual loss [3].

\section{Patients and Methods}

In Kasr Al-Ainy Hospital, Cairo University; from September 2014 till August 2015; we worked on our prospective observational case series study; which included 45 eyes presented with rhegmatogenous retinal detachement.

All eyes underwent successful reattachment surgery. The patients were selected from the Ophthalmology Outpatient Clinic of Kasr Al-Ainy Teaching Hospital. The patients ages ranged from 18 years and older and were given their written informed consent. 


\section{Exclusion criteria:}

- Patients with a pre-existing macular pathology such as AMD, macular hole, diabetic maculopathy and traumatic maculopathy.

- Tractional and exudative retinal detachment.

- Recurrence of the detachment.

- Pathological eye disease such as uveitis, glaucoma or retinal vascular occlusive diseases.

- Significant post-operative media opacity interfering with FAF imaging.

Pre-operative assessment:

All patients underwent complete ophthalmological examination before surgery, including:

- Best corrected visual acuity (according to the Snellen chart).

- Slit lamp examination.

- IOP assessment (by applanation tonometer).

- Dilated fundus examination by binocular indirect slit lamp bimicroscopy and indirect ophthalmoscopy.

\section{Surgical approach:}

- Vitrectomy (23G) was done.

- Choice of tamponade was decided intraoperative according to each case. PFCL/Silicone oil (1000 cs) exchange was done in most of vitrectomy cases.

- Laser retinopexy (endolaser photocoagulation) was applied 360 degrees and to all the breaks.

- Phakic patients with any degree of lens opacity or at presbyopic age; underwent phacoemulsification and PCIOL implantation.

\section{Post-operative examination and follow-up:}

Complete routine ophthalmological examination was done on the first week post-operative, then 1 month post-operative, including:

- BCVA (using Snellen chart).

- Slit lamp examination.

- Dilated fundus examination using indirect ophthalmoscopy and binocular slit lamp bimicroscopy.

- IOP assessment.

\section{Post-operative investigations:}

Macular FAF imaging using TOPCON 3D OCT2000 FA plus was done at one to three months intervals post-operative; after stabilizing the retinal reattachment.
- The filter used in autofluorescence was the Infrared Spaide Filter.

- Baseline colored fundus photography and RedFree images were recorded.

Clinically, the macula was defined as the area of retina located between the temporal vascular arcades, approximately $6 \mathrm{~mm}$ in diameter, centered at the fovea. The fovea was defined as the central retinal depression, approximately $4.0 \mathrm{~mm}$ temporal and $0.8 \mathrm{~mm}$ inferior to the center of the optic disc, and was approximately $1.5 \mathrm{~mm}$ in diameter.

The primary outcome is evaluating the microstructural and anatomical details of the macula obtained by fundus autofluorescence and correlating the findings with visual outcome following successful repair of RRD.

\section{Statistical analysis:}

Data were coded and entered using the statistical package SPSS Version 22. Data was summarized using mean, standard deviation, median minimum and maximum in quantitative data and using frequency (count) and relative frequency (percentage) for categorical data. Comparison between preoperative and post-operative visual acuity was done using the non-parametric Wilcoxon signed rank test. $p$-values less than 0.05 were considered as statistically significant.

\section{Results}

Forty-five eyes were successfully attached following RD surgery and were enrolled in the study.

Duration of $R D$ : The duration of retinal detachment varied among the patients from 1 week to 16 weeks with a mean of 4.614 .16 weeks. The duration of retinal detachment showed statistically significant correlation with final visual outcome (BCVA) $(r=0.503, p$ 0.001) Fig. (1).

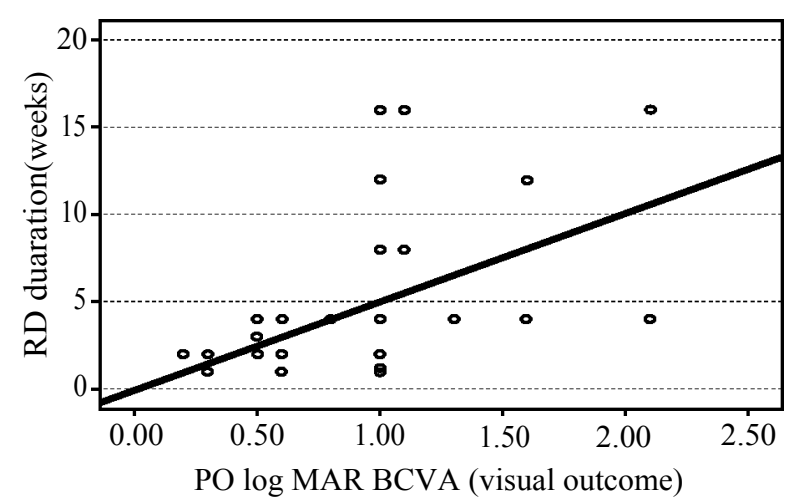

Fig. (1): Correlation between RD duration and log MAR $\operatorname{BCVA}(r=0.503, p 0.001)$. 
- The pre-operative Macula status, RD break type and RD extent are shown in (Table 1) and showed no statistical significance with BCVA.

Table (1): Clinical data of patients with rhegmatogenous retinal detachment.

\begin{tabular}{ll}
\hline & No. of eyes $(\%)$ \\
\hline Macula status: & $4(8.9 \%)$ \\
On & $41(91.9 \%)$ \\
Off & \\
Extent and height of RD: & $19(42.2 \%)$ \\
Total & $26(57.8 \%)$ \\
Subtotal & \\
Type of the break: & $37(82.2 \%)$ \\
Horse shoe & $6(13.3 \%)$ \\
Hole & $2(4.4 \%)$ \\
Dialysis &
\end{tabular}

\section{Surgical outcome:}

Forty-three eyes (95.6\%) achieved complete post-operative reattachment with Single Operation Success Rate (SOSR) and two eyes (4.4\%) showed juxtafoveal lamellar macular hole.

\section{Visual outcome:}

Mean post-operative $\log$ MAR BCVA was 0.93 0.42 .

Interpretation of FAF macular imaging following surgery:

\section{-Hyper-autofluorescence:}

Eighteen eyes showed hyper-autofluorescence at the macula (40\%). Figs. (2A-D) show characteristics of hyper-autofluorescence. The values of BCVA showed statistically significant difference between patients with hyper-autofluorescence and those without ( $p=0.015)$ Fig. (3).

\section{-Hyper-autofluorescence characteristics:}

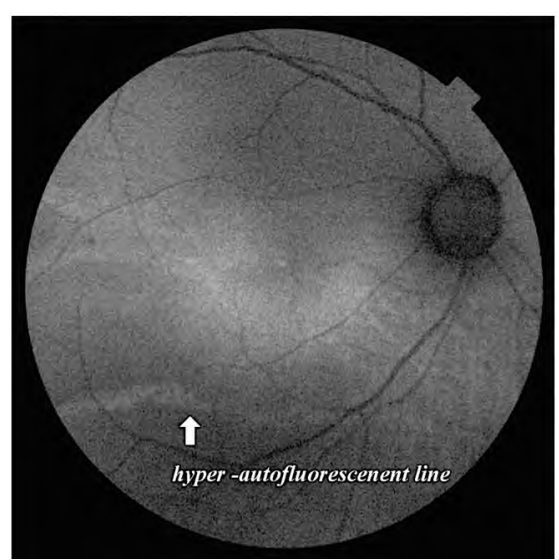

Fig. (2A): FAF of the right eye showing macular hyperautofluorescence consistent with RPE stress cells and increase lipofuscin activity and Inferior temporal persisitent line of demarcation coinciding with Hyper-autofluorescent Leading Edge (HLE).

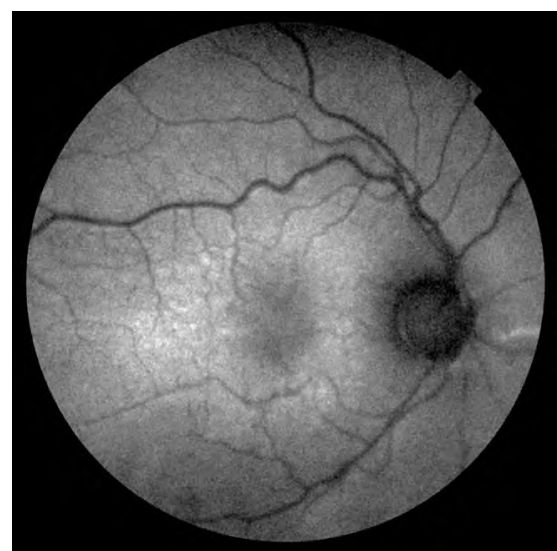

Fig. (2B): FAF image of the right eye showing macular hyperautofluorescence consisted with RPE stress cells and increase lipofuscin activity and Hyper autofluorescent line in the nasal retina coinciding with persistent line of demarcation.

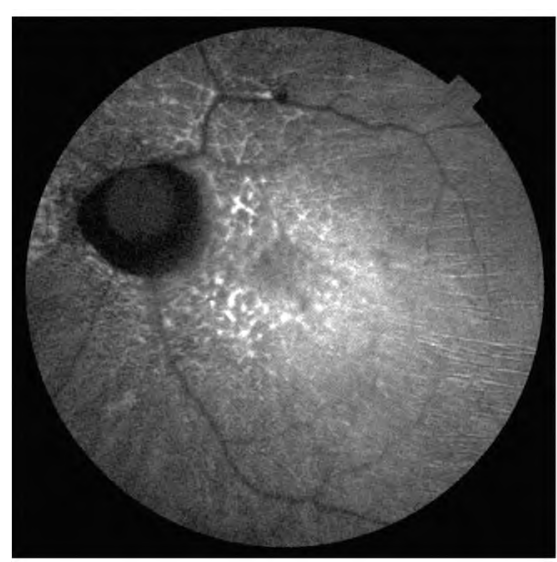

Fig. (2C): FAF of the left eye showing multiple granular hyper-autofluorescet spots at the macula consisted with RPE stress cells, and multiple radial hyperautofluorescent retinal folds coinciding with RPEchoriocapillaries complex irregularities (outer retinal folds).

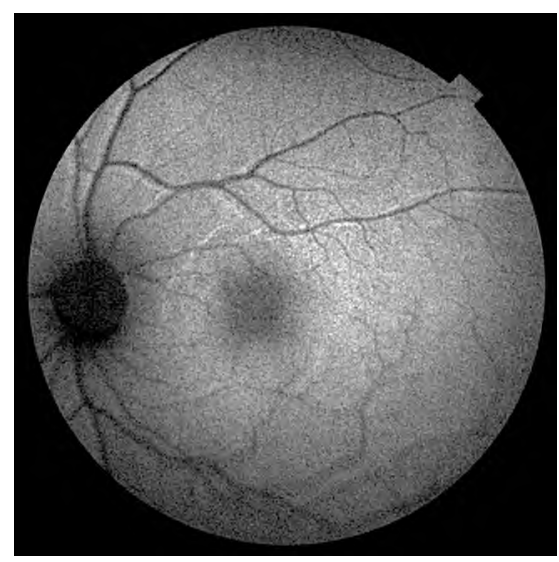

Fig. (2D): FAF image of the left eye showing hyperautofluorescent retinal lines parallel to the retinal vessels denoting slightly shifting of the macular position post-operative. 


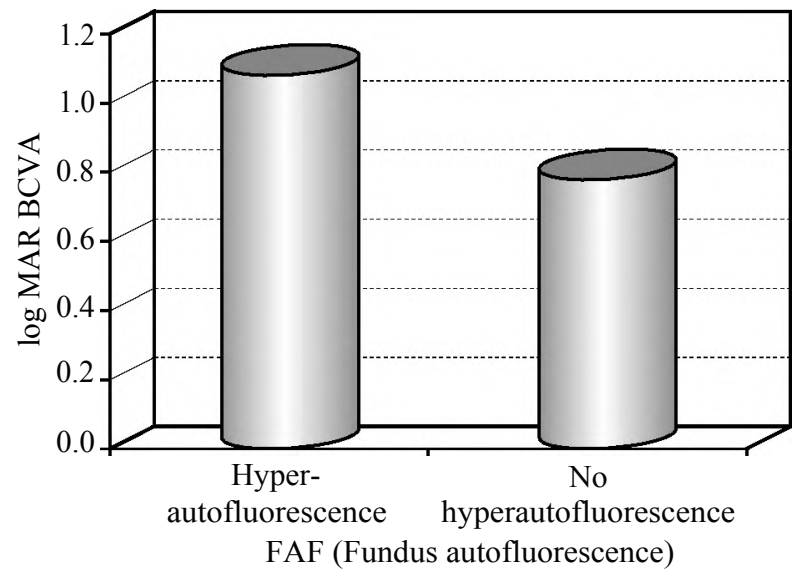

Fig. (3): Log MAR BCVA difference between eyes with fundus hyper-autofluorescent and eyes without $(p=0.015)$.

\section{- Blocked autofluorescence:}

Three eyes showed blocked autofluorescence coinciding with myopic chorioretinal degenerations and atrophy (6.7\%) (Fig. 4).

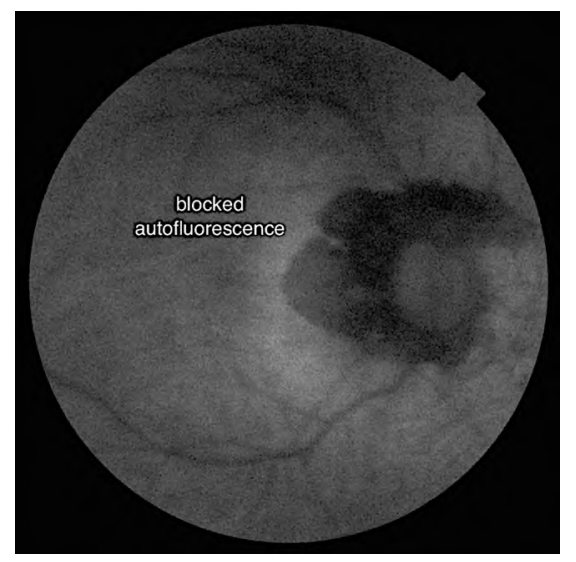

Fig. (4): FAF image of the right eye showing blocked autofluorescence.

\section{- Iso-autofluorescence:}

Twenty-four eyes showed no evident changes on FAF images (53.3\%) (Fig. 5).

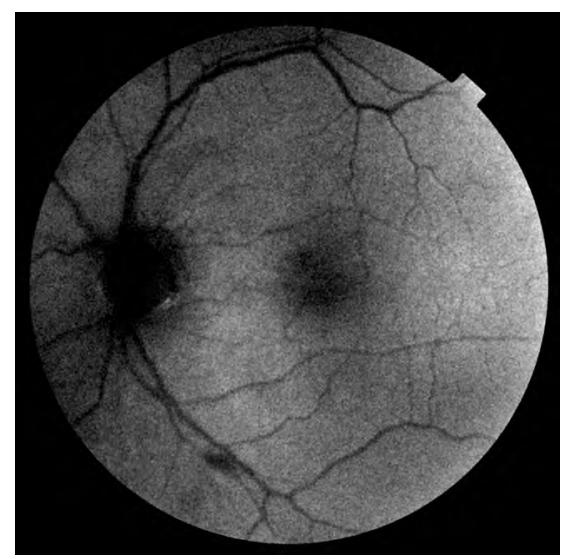

Fig. (5): FAF image of the left eye showing iso-autofluorescence.

\section{Discussion}

Rhegmatogenous Retinal Detachment (RRD) leads to anatomical distortion of the human retina and consequently, visual impairment. Advances in vitreoretinal surgical techniques during the last 30 years resulted in high percentages of anatomical success in RRD repair surgery. Despite the high percentages of satisfactory anatomic results, very often the functional results still remain puzzling [4].

Incomplete visual recovery after anatomically and clinically successful repair has been attributed to several pre-operative and postoperative factors. Several studies analyzed the pre-and post-operative factors in order to identify the factors that could potentially affect the post-operative functional outcome [4]

In 2007, Doyle and colleagues [5] noted that good pre-operative visual acuity is the only significant factor predictive of visual outcome $(p<0.001)$, which was mentioned by previous studies. In our study the mean preoperative log MAR visual acuity was $2.02 \pm 0.3$ and showed statistically significance difference with the mean post-operative log MAR $\operatorname{BCVA}(0.93 \pm 0.42)(p<0.001)$.

There was no significant correlation between preoperative visual acuity and post-operative BCVA. Longer follow-up over years may be necessary to demonstrate gradual improvement in visual function.

Older studies suggested that the duration of macular detachment should be limited to a maximum of 7-9 days if possible after which the visual results of successful primary reattachment will be adversely affected [6]. However, these studies used almost entirely scleral buckling without vitrectomy.

There is conflict between studies involving vitrectomy for retinal detachment as to whether duration of macular detachment is or is not a significant predictor of visual outcome [7].

In our study, the duration of macular detachment prior surgical intervention showed statistically significant correlation with post-operative $\log$ MAR $\operatorname{BCVA}(r=0.503, p 0.001)$. This result matches well with the studies done by Van de Put and colleagues [8]

Our hypothesis suggests that there may be an association between FAF changes and morphological and visual outcome. In our study we observed the autofluorescent changes at the macula and correlated these changes with post-operative BCVA. 
FAF imaging is able to map metabolic changes at the level of the Retinal Pigment Epithelium (RPE) noninvasively in vivo. However, the observed autofluorescence signal is a summation of not only the autofluorescence originating from the RPE but also that from more anterior ocular structures including the overlying neuroretina [9].

Increased levels of AF indicate increased presence of oxidative stress and increased metabolic activity as the RPE enters a preapoptotic state. Therefore, AF is a valuable modality for assessing the function of RPE cells and the viability of the retinal function [10].

Another suggested pathogenesis of hyperautofluorescence following RRD repair was outer retinal disruption. This might result in increased autofluorescence due to a window defect as a result of photopigment loss over an intact RPE. Recognizing that increased FAF can occur in the absence of increased fundus fluorophores may help clinicians to detect and more precisely monitor early photoreceptor damage. In some patients, these findings may provide an anatomical correlate of persistent suboptimal visual function despite relatively normal RPE structure [11].

In Conclusion; incomplete visual recovery after anatomically and clinically successful repair of RRD is attributed to several factors. Fundus autofluorescence is a recent valuable, non-invasive imaging technique; it detects the function and health of the photoreceptor and the RPE layers showing great advantage in analyzing the macular function abnormality.

\section{References}

1- HAGIMURA N., IIDA T., SUTO K., et al.: Persistent foveal retinal detachment after successful rhegmatogenous retinal detachment surgery. Am. J. Ophthalmol., 133: 51620, 2002.

2- SEO J.H., WOO S.J., PARK K.H., et al.: Influence of persistent submacular fluid on visual outcome after successful scleral buckle surgery for macula-off retinal detachment. Am. J. Ophthalmol., 145: 915-22, 2008.

3- WITMER M.T., CHO M., FAVARONE G., et al.: Ultrawide-field autofluorescence imaging in non-traumatic rhegmatogenous retinal detachment. Eye (Lond), 26: 1209-16, 2012.

4- TSILIMBARIS M.K., CHALKIA A., TSIKA C., et al.: Clinical and spectral-domain optical coherence tomography findings of patients with incomplete visual recovery after anatomically successful retinal detachment surgery. J. Ophthalmol., Article ID 420401, 5 pages, 2015.

5- SHARMA T., CHALLA J.K., RAVISHANKAR K.V., et al.: Scleral buckling for retinal detachment. Predictors for anatomic failure. Retina, 14: 338-43, 1994.

6- HASSAN T.S., SARRAFIZADEH R., RUBY A.J., et al.: The effect of duration of macular detachment on results after the scleral buckle repair of primary, macula-off retinal detachments. Ophthalmology, 109: 146-52, 2002.

7- SPEICHER M.A., FU A.D., MARTIN J.P., et al.: Primary vitrectomy alone for repair of retinal detachments following cataract surgery. Retina, 20: 459-64, 2000.

8- VAN DE PUT M.A., CROONEN D., NOLTE I.M., et al.: Post-operative recovery of visual function after maculaoff rhegmatogenous retinal detachment. PLoS One, 9: e99787, 2014.

9- SCHMITZ-VALCKENBERG S., HOLZ F.G., BIRD A.C., et al.: Fundus autofluorescence imaging: Review and perspectives. Retina, 28: 385-409, 2008.

10-LOIS N. and FORRESTER J.V.: Fundus Autofluorescence Philadelphia, PA: Lippincott Williams and Wilkins, 2009.

11- FREUND K.B., MREJEN S., JUNG J., et al.: Increased fundus autofluorescence related to outer retinal disruption. J.A.M.A. Ophthalmol., 131: 1645-9, 2013. 


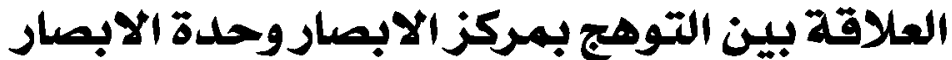

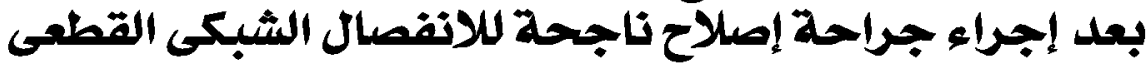

يؤدى إنفصال الشبكية القطعى إلى التشتت التشريحى لشبكية العين، وبالتالى إلى قصود فى حدة الإبصار. ورغم معدلات النجاح الجراحى والتشريحى الممتازة مع طرق العلاج السائدة، لا زالت نتائج حدة الإبصار غير مرضية فى بعض الحالات. ويعد (التوهجع الذاتى لقاع العين) وسيلة تصوير غير غازية قادرة على تقييم الحالة الوظيفية والتشريحية للشبكية. الهدف من هذه الدراسة هو بحث العلاقة التركيية الوظيفية لمركز الإبصار عن طريق إيجاد العلاقة بين نتائج (التوهج الذاتى لقاع العين) ووحدة الإبصار النهائية، وذلك بعد إجراء جراحة إصلاح ناجحة للإنفصال الشبكى القطعى.

ويعزى عدم إستعادة كفاءة حدة الإبصار بعد النجاح التشريحى والإكلينيكى لجراحة الإنفصال الشبكى القطعى إلى عدة آسباب.

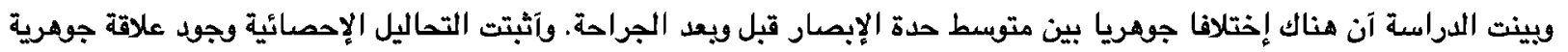

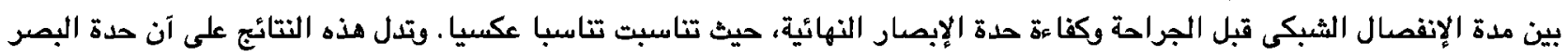

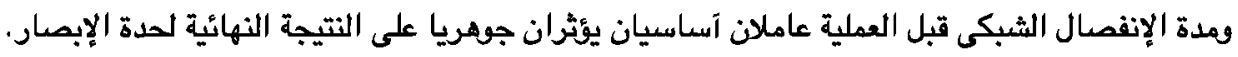

وكذلك بينت هذه الدراسة آن هناك فرقا جوهريا في حدة الإبصار النهائية بين الحالات التى ظهر بها زيادة فى التههج الذاتى لمركز الإبصار عن تلك التى لم يظهر بها زيادة في التهـجع.

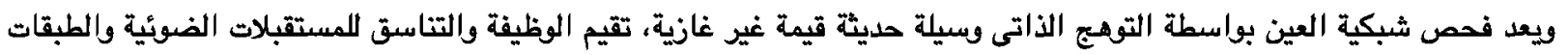

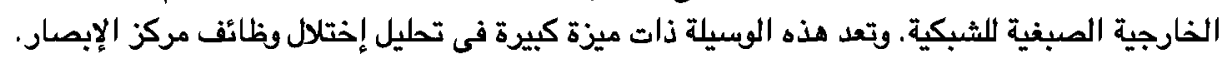

